\title{
Influence of perioperative hypothermia on blood clotting in children
}

\author{
Trckova A, Stourac P \\ Department of the Paediatric Anaesthesiology and Intensive Care, University Hospital Brno and Faculty \\ of Medicine, Masaryk University Brno, Czech Republic. petr.stourac@gmail.com
}

\begin{abstract}
OBJECTIVES: The decrease of body temperature is one of the causes of blood clotting disorders.

BACKGROUND: Accidental hypothermia during anesthesia is a common condition and children, especially newborns, are the most sensitive patients to the side effects of hypothermia.

METHODS: Web of Science, SCOPUS and PubMed search was performed to retrieve both original and review articles addressing both, hypothermia during surgery and coagulation disorder in pediatric patients.

RESULTS: The most common perioperative hypothermia is in pediatric patients during cardio surgical operations using cardiopulmonary bypass, which corresponds to the largest number of published articles dealing with the relationship of perioperative hypothermia and coagulopathy in children.

CONCLUSION: More detailed information on the temperature when the patient is already at risk of developing a clinically significant coagulation disorder and differentiating other factors affecting hemostasis is a subject of further investigation (Tab. 1, Fig. 1, Ref. 20). Text in PDF www.elis.sk.

KEY WORDS: pediatric surgery; coagulation; bleeding; temperature management; perioperative hypothermia.
\end{abstract}

\section{Introduction}

Pediatric patients are a risk group for development of perioperative hypothermia (1). The decrease of body temperature is one of the causes of blood clotting disorders, which can occur in patients during and after surgery. Coagulation disorder during hypothermia depends on the degree of hypothermia (2). The most common cause of the perioperative hypothermia in pediatric patients is the use of cardiopulmonary bypass, where the hypothermia is induced and deep. Therefore, the relation between hypothermia and clotting disorder is the most frequently observed one. However, coagulation disorder is due to many factors, and it is difficult to distinguish their individual roles (3).

The aim was to evaluate the influence of temperature on coagulation in children perioperatively.

\section{Methods}

Available literature was searched in the Web of Science, SCOPUS, and PubMed databases as recommended by PRISMA statement. The search was limited to articles published from 1992 until July 2017.

${ }^{1}$ Department of the Paediatric Anaesthesiology and Intensive Care, University Hospital Brno and Faculty of Medicine, Masaryk University Brno, Czech Republic

Address for correspondence: P. Stourac, MD, PhD, Cernopolni 212/9, CZ-613 00 Brno, Czech Republic.

Acknowledgement: This review was financially supported by grant MZČR-RVO (FNBr, 65269705).
Potentially relevant articles were identified by manual search. Language restriction was used - only articles found in English, German or Czech language were used. Only human studies were included. Studies in only non-pediatric patients were excluded; however, if the study group included children and adults as well, we did not reject such study. Studies that continued with hypothermia postoperatively and were evaluated for coagulation were also not rejected.

\section{Results}

The search process and its results are shown in detail in the flow chart (Fig. 1). There were 15 articles dealing with the relationship between perioperative hypothermia and coagulation disorder. 13 of these articles were focused on pediatric cardiac surgery patients, 1 was about newborns with surgical procedure for necrotizing enterocolitis, who were in hypothermia even 48 hours after the intervention and 1 studied patients (both children and adults) undergoing orthopedic surgery.

\section{Discussion}

The included articles did not have the primary objective to evaluate the influence of body temperature on coagulation in children. The most common primary objective was the perioperative hypothermia in pediatric patients during cardiosurgical operations using cardiopulmonary bypass, which corresponded to the largest number of published articles dealing with the relationship of perioperative hypothermia and coagulopathy in children. From other articles, not related to hypothermia and coagulation disorder, perioperative hypothermia was reported in neurosurgery, liver 

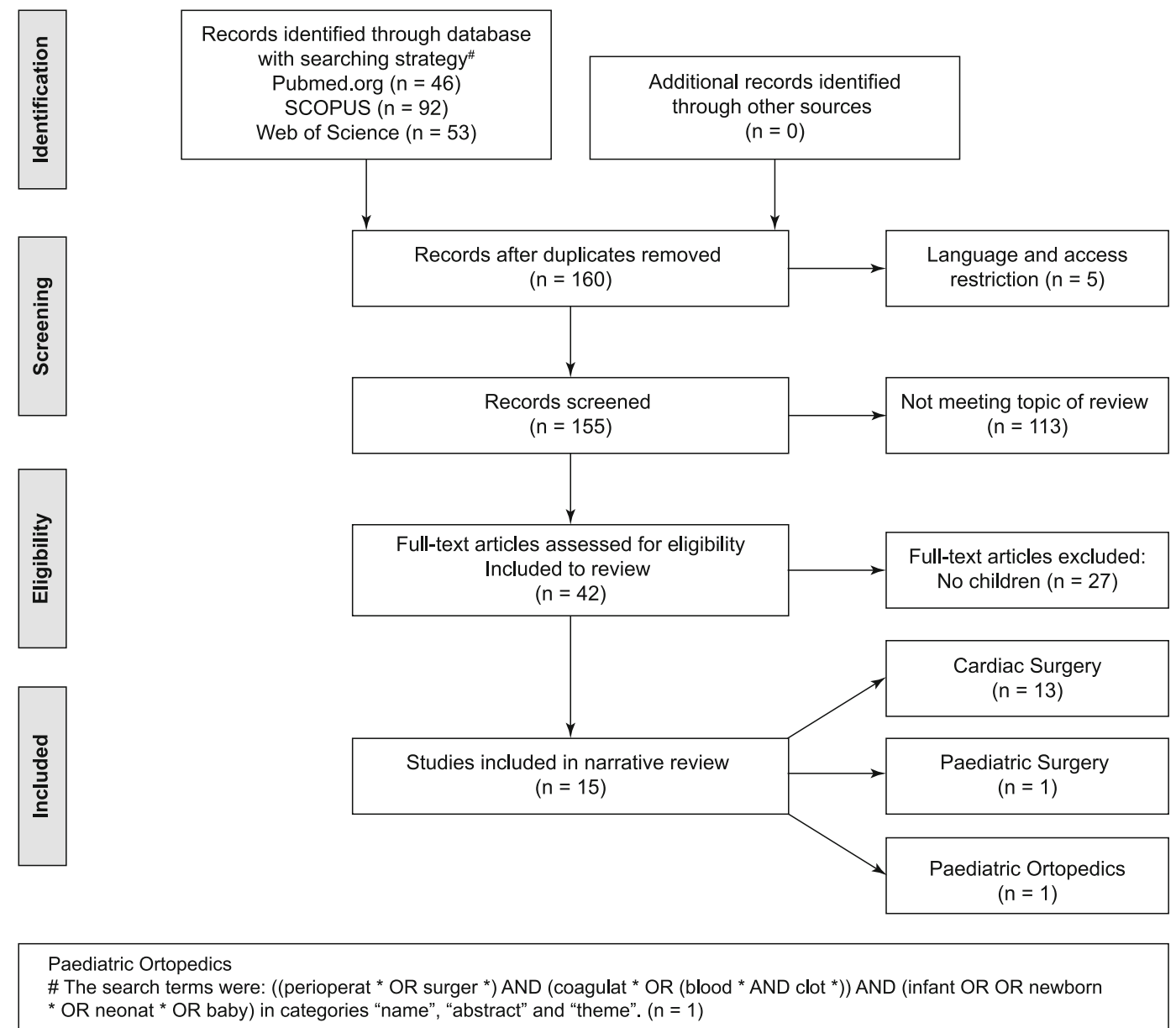

Fig. 1. The search process and its results.

transplantation, large orthopedic surgery, neonatal surgeries and traumatology operations. Not only in these surgeries, there was a certain degree of perioperative hypothermia, which could affects coagulation, blood loss and the overall outcome of the patient.

\section{Hypothermia}

The core temperature varies between $36.5^{\circ} \mathrm{C}$ and $37.5^{\circ} \mathrm{C}$. The mechanism of targeted temperature setting is unclear, involving neurotransmitters including noradrenaline, dopamine, serotonin, acetylcholine, prostaglandin E1 and other neuropeptides. Another factors affecting temperature are, for example, circadian rhythm, exercise, anesthetics and other medications (4). Hypothermia is a condition, in which the temperature control mechanisms fail due to low temperature. Hypothermia can be accidental or therapeutic, primary or secondary. Hypothermia can be divided by severity to light $\left(35-32^{\circ} \mathrm{C}\right)$, moderate $\left(32-28^{\circ} \mathrm{C}\right)$ and severe (below $28^{\circ} \mathrm{C}$ ). Another scoring system designed for the patients with trauma has 4 degrees: I: $36-35{ }^{\circ} \mathrm{C}$, II: $34-32{ }^{\circ} \mathrm{C}$., III: $32-28{ }^{\circ} \mathrm{C}$ and IV: below $28{ }^{\circ} \mathrm{C}$. This division seems to be more appropriate because it emphasizes on the effect of the temperature to the outcome of the patient, as this is along with acidosis and coagulopathy a part of the lethal triad in trauma (5). Another possible division is the UIAA MEDDCOM scale designed for the first-contact medicine and for the use of an untrained rescuer: 1 st grade - the patient is conscious and shakes $\left(35-32{ }^{\circ} \mathrm{C}\right)$; 2nd grade - the affected person is sleepy and does not tremble (32-28 $\left.{ }^{\circ} \mathrm{C}\right), 3$ rd grade - the affected person is unconscious, but has vital functions $\left(28-24^{\circ} \mathrm{C}\right)$, 4th grade -absence of vital functions, apparent death $\left(24-13.7^{\circ} \mathrm{C}\right)$, and 5 th grade - secondary death for irreversible hypothermia $\left(<13{ }^{\circ} \mathrm{C}\right)(6)$.

\section{The effect of hypothermia on the organism}

Hypothermia is an independent risk factor for mortality, associated with cardiovascular system and coagulation involvement, acid-base balance disorder and respiratory distress (7) (Tab. 1).

\section{Hypothermia and haemostasis}

The decrease of body temperature is one of the causes of blood clotting disorders. Hypothermia results in hemoconcentration and increased blood viscosity. Thrombocytopenia is reversibly affected by temperature and platelet function due to reduced platelet activation rather than intrinsic functional impairment (8). Coagulation 


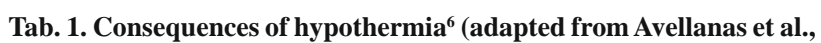
Management of severe accidental hypothermia).

Central nervous system

$<32{ }^{\circ} \mathrm{C}$ - disorder of consciousness, lowering of EEG amplitude

Depression of respiration, loss of cough reflex

$<28{ }^{\circ} \mathrm{C}$ coma

$<18{ }^{\circ} \mathrm{C}$ flat line on EEG

Cardiovascular system

hypotension, lowering of heart output, sinus bradycardia, sinus fibrillation and flutter, $\angle 28^{\circ} \mathrm{C}$ ventricular tachycardia and asystolia

ECG: alteration ST, long QT, $<31^{\circ} \mathrm{C}$ Osborns J-wave

Respiratory system

tachypnea and subsequent bradypnoea, low respiratory volumes, hypoventilation, hypoxemia, hypocapnia

increasing solubility of $\mathrm{O}_{2}$ a $\mathrm{CO}_{2}$

reducing oxygen consumption: $1^{\circ} \mathrm{C}-6 \%$

initially hyper secretion, decreased mucocilliary activity, atelectase

Gastrointestinal system

pancreatitis, ileus, lowering liver enzymes activity, gastritis

hyperglycemia

Renal system

pollakisuria, renal failure

infection, sepsis

Toxicity of vasoactive drugs

alteration adrenergic receptors

disorder of drug clearance

factors work optimally at $37^{\circ} \mathrm{C}$. Hypothermia leads to decreased functions of the coagulation factors and fibrinogen production failure at temperatures below $33^{\circ} \mathrm{C}$. Temperatures below $33^{\circ} \mathrm{C}$ also inhibit thrombin, glycoprotein Ib-IX complex, platelet aggregation, and thromboxane B2 production (7). In an in vitro study of gradual decrease of temperature, there was an increased breakdown of the coagulation process, failure of adhesion and platelet aggregation occurred at $33{ }^{\circ} \mathrm{C}$, at a temperature below $33^{\circ} \mathrm{C}$, enzyme activity disorder occurred (9). Standard coagulation assays such as PT and aPPT are performed at standard temperature $37^{\circ} \mathrm{C}$, aPTT change occurs only with severe hypothermia. Changes in the coagulation system should be more effective in capturing the bed side of the TEG/ROTEM method (10). The advantages of thrombelastometry is the shorter time of the examination and the possibility of more targeted therapy of the coagulation disorder (11).

\section{Perioperative hypothermia}

Unintentional hypothermia during anesthesia is the most common perioperative thermal disorder (12). The decrease of temperature during general anesthesia is dependent on the type and amount of anesthetics usage, the extent of surgical intervention and ambient temperature. During the first hour of anesthesia, there is a rapid decrease of the temperature by $1-1.5^{\circ} \mathrm{C}$, during the next $2-3$ hours, the decrease is slower until it reaches the plateau phase (12). There are special indications for perioperative hypothermia - in limited indications it has benefits for patients according to the clinical trials. Hypothermia is used to reduce tissue metabolism or protect brain functions (13). An example is the use of therapeutic hypothermia in patients after cardiac arrest (14), neonatal asphyxia, cerebral trauma, during intracranial aneurysm surgery or aortic aneurysm surgery (1).

\section{Perioperative hypothermia in children}

The susceptibility of pediatric patients to hypothermia is due to a combination of decreased production and increased heat loss during surgery, which is greater than that in adult patients. The risk factors for hypothermia that play a role in children are, for example, a relatively larger surgical field size compared to body surface area and a thinner layer of subcutaneous fatty tissue. Newborns are the most sensitive group to the side effects of accidental perioperative hypothermia. CNS immaturity leads to sensitivity to environmental temperature fluctuations. Cold stress increases sympathetic activity and oxygen consumption, which can lead to metabolic acidosis, hypoglycemia and other consequences (1).

\section{Prevention of perioperative hypothermia and methods of patient temperature measurement}

Patients lose the heat through the skin to the environment by radiation, conduction and convection, evaporation. The largest part $-60 \%$ of heat - is lost by radiation (4). Avoiding heat loss by covering the patient is a passive method of warming them. Sufficient coverage of the patient's surface is mostly inadequate, heat losses through the airway reach up to $50 \%$ of the total heat loss (15). Especially in children, a combination of different methods is often needed to achieve normothermia (16). When the active heating is used, there could be a risk of thermal injury when too high temperatures are applied or when a device without feedback is used.

Patient's temperature monitoring is a part of the vital signs monitoring and should not be neglected. It is used to monitor perioperative hypothermia or to prevent overheating. Body core temperature can be measured, for example, in the distal part of the esophagus, in the nasopharynx, in the pulmonary artery. Some methods used clinically are acceptable for measuring body temperature - such as bladder or rectal measurements - they have their limits and can be considered as a „temperature near body temperature“ (17).

\section{Complications of perioperative hypothermia}

Complications of postoperative hypothermia include primarily impaired perioperative and post-operative status, slowed healing and prolonging hospitalization and, last but not least, unpleasant sensations for the patient.

The most serious complications of perioperative hypothermia are cardiac arrhythmias and myocardial infarction, coagulation disorders that increase bleeding and need for transfusions. There could be a healing disorder and a more frequent incidence of surgical wound infection. There is an extension of the anesthetic effect. Tremor as a mechanism for increasing body temperature occurs in patients with anesthetic withdrawal and, in addition to discomfort, leads to increased oxygen consumption (18).

The effect of hypothermia on the pharmacokinetics of anesthetics

Hypothermia prolongs the effect of the majority of non-depolarizing muscle relaxant and has a slightly less effect on depolarizing relaxation. Increased solubility of inhaled anesthetics at reduced temperature results in a slight decrease of MAC, which is reduced by $5 \%$ for each $1{ }^{\circ} \mathrm{C}$ below normal temperature. The plasma concentration of propofol is increased. Opioid analgesics 
have an extended effect (2). Opioids also cause that the target body temperature limits increase by $0.2-4{ }^{\circ} \mathrm{C}$ in the hypothalamus, so the heat and cold respond is weak. Midazolam and probably also other benzodiazepines have little or no effect on the body temperature (4).

\section{Coagulation tests}

The ability of blood to clot is verified by coagulation tests. For example, standard coagulation tests include prothrombin time (PT) - Quick's test and its normalized INR ratio for external coagulation system monitoring or activated partial thromboplastin time (aPTT) used to monitor the internal coagulation system. These tests are performed from blood plasma. Another type of coagulation examinations are the viscoelastic methods of rotational thrombolastometry ROTEM and TEG thromboelastography, which are used for the examination of the whole blood. Their benefits include, for example, a rapid availability of the results, where the first valid values are available in less than 15 minutes, and a smaller volume sample (19). Using the ROTEM method, we can obtain several types of examinations. In-TEM is an examination of the internal pathway of coagulation, it is sensitive to high doses of heparin, Ex-TEM containing thromboplastin outer pathway activator, FibTEM to examine functional fibrinogen, Hep-TEM test to investigate the effect of heparin and Ap-TEM to detect the presence of fibrinolysis. Another test is Na-TEM (non-activated test) without added activator, which should be most sensitive to the presence of coagulation disorders, but is not standardized yet (20).

\section{Learning point}

- Temperatures below $33^{\circ} \mathrm{C}$ leads to failure of fibrinogen and coagulation factors production (7). Failure of adhesion and platelet aggregation occurred also at $33^{\circ} \mathrm{C}(9)$.

- Unintentional hypothermia during pediatric anesthesia is the most common perioperative thermal disorder (12).

- Newborns are the most sensitive group to the side effects of accidental perioperative hypothermia. Cold stress can lead to metabolic acidosis, hypoglycemia and other consequences, in addition to hypocoagulation (1).

- Patient's temperature monitoring is a part of the vital signs monitoring and should not be neglected.

\section{References}

1. Hart SR, Bordes B, Hart J, Corsino D, Harmon D. Unintended Perioperative Hypothermia. Ochsner J 2011; 11 (3): 259-270.

2. Horosz B, Malec-Milewska M. Inadvertent intraoperative hypothermia. Anaesth Intens Ther 2013; 45 (1): 38-43. doi: 10.5603/AIT.2013.0009.

3. Durandy Y. Use of blood products in pediatric cardiac surgery. Artif Organs 2015; 39 (1): 21-27. doi: 10.1111/aor.12447.

4. Díaz M, Becker DE. Thermoregulation: physiological and clinical considerations during sedation and general anesthesia. Anesth Prog 2010; 57 (1): 25-32. doi: 10.2344/0003-3006-57.1.25.

5. Kirkpatrick AW, Chun R, Brown R, Simons RK. Hypothermia and the trauma patient. Can J Surg J Can Chir 1999; 42 (5): 333-343.
6. Avellanas ML, Ricart A, Botella $\mathbf{J}$ et al. Management of severe accidental hypothermia. Med Intens 2012; 36 (3): 200-212. doi: 10.1016/j. medin.2011.12.005.

7. Perlman R, Callum J, Laflamme C et al. A recommended early goaldirected management guideline for the prevention of hypothermia-related transfusion, morbidity, and mortality in severely injured trauma patients. Crit Care Lond Eng 2016; 20 (1): 107. doi: 10.1186/s13054-016-1271-z.

8. Van Poucke S, Stevens K, Marcus AE, Lancé M. Hypothermia: effects on platelet function and hemostasis. Thromb J 2014; 12 (1): 31. doi: 10.1186/s12959-014-0031-z.

9. Wolberg AS, Meng ZH, Monroe DM, Hoffman M. A systematic evaluation of the effect of temperature on coagulation enzyme activity and platelet function. J Trauma 2004; 56 (6): 1221-1228.

10. De Robertis E, Kozek-Langenecker SA, Tufano R, Romano GM, Piazza O, Zito Marinosci G. Coagulopathy induced by acidosis, hypothermia and hypocalcaemia in severe bleeding. Minerva Anestesiol 2015; 81 (1): 65-75.

11. Haas T, Spielmann N, Mauch $\mathbf{J}$ et al. Comparison of thromboelas-

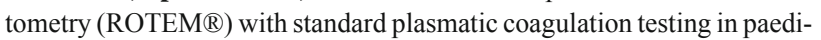
atric surgery. Br J Anaesth 2012; 108 (1): 36-41. doi: 10.1093/bja/aer342.

12. Huang C-J, Chen C-L, Tseng C-C et al. Maintenance of normothermia at operation room temperature of 24 degrees $\mathrm{C}$ in adult and pediatric patients undergoing liver transplantation. Transpl Int Off J Eur Soc Organ Transplant 2005; 18 (4): 396-400. doi: 10.1111/j.1432-2277.2004.00040.x.

13. Stocker CF, Shekerdemian LS, Horton SB et al. The influence of bypass temperature on the systemic inflammatory response and organ injury after pediatric open surgery: A randomized trial. J Thorac Cardiovasc Surg 2011; 142 (1): 174-180. doi: 10.1016/j.jtcvs.2011.01.059.

14. Kobr J, Pizingerova K, Sasek L, Fremuth J, Fikrlova S. Induced therapeutic hypothermia following cardiac arrest in children. Bratisl Med J 2011; 112 (2): 92-96.

15. Horosz B, Malec-Milewska M. Methods to prevent intraoperative hypothermia. Anaesthesiol Intensive Ther 2014; 46 (2): 96-100. doi: 10.5603/ AIT.2014.0019.

16. Witt L, Dennhardt N, Eich C et al. Prevention of intraoperative hypothermia in neonates and infants: results of a prospective multicenter observational study with a new forced-air warming system with increased warm air flow. Pediatr Anesth 2013; 23 (6): 469-474. doi: 10.1111/pan.12169.

17. Sessler DI. Temperature monitoring and perioperative thermoregulation. Anesthesiology 2008; 109 (2): 318-338. doi: 10.1097/ ALN.0b013e31817f6d76.

18. Billeter AT, Hohmann SF, Druen D, Cannon R, Polk Jr. HC. Unintentional perioperative hypothermia is associated with severe complications and high mortality in elective operations. Surgery 2014; 156 (5): 1245-1252. doi: 10.1016/j.surg.2014.04.024.

19. Straub A, Schiebold D, Wendel HP et al. Using reagent-supported thromboelastometry (ROTEM) to monitor haemostatic changes in congenital heart surgery employing deep hypothermic circulatory arrest. Eur J Cardio-Thorac Surg Off J Eur Assoc Cardio-Thorac Surg 2008; 34 (3): 641-647. doi: 10.1016/j.ejcts.2008.05.028.

20. Durila M. Význam rotačnej tromboelastometrie (ROTEM) v manažmente perioperačného krvácania. Anesteziol Intenziv Med 2016; 27 (4): 259-266.

Received January 13, 2018. Accepted February 22, 2018. 